7. Reprod. Fert. (1970) 23, 411-414

\title{
THE OESTROUS CYCLE OF ZEBU AND SANGA BREEDS OF CATTLE IN CENTRAL AFRICA
}

\author{
A. M. RAKHA, G. IGBOELI AND D. HALE* \\ Agricultural Research, National Council for Scientific Research, \\ P.O. Box 49, Chilanga, Lusaka, Zambia
}

(Received 22nd December 1969)

\begin{abstract}
Summary. A total of 333 oestrous cycles was observed in fifty-five sexually mature cattle of Central African breeds. Silent ovulation accounted for $13 \%$ of the cycles. The normal cycle lengths averaged $21 \cdot 89 \pm 1 \cdot 64,22 \cdot 68 \pm 3 \cdot 68$ and $24 \cdot 25 \pm 2 \cdot 27$ days for the Angoni, Barotse and Boran breeds, respectively. The lengths of the corresponding oestrous periods were $16 \cdot 26 \pm 1.08,17.43 \pm 1.18$ and $14.79 \pm 3.03 \mathrm{hr}$. Ovulation occurred $31.50 \pm 1.45 \mathrm{hr}$ from the time of onset of oestrus. Most animals came into heat around sunrise and sunset. Cervical changes were photographed.
\end{abstract}

\section{INTRODUCTION}

Cows which have been adapted to tropical conditions are generally considered to mature late and to have irregular oestrous cycles associated with a short oestrus and poor signs of heat. In order to test these assumptions, the oestrous cycle was studied in the Angoni, Barotse and Boran breeds of cattle found in Central Africa. The increasing application of artificial insemination in this area underlines the necessity for this type of study.

\section{MATERIAL AND METHODS}

A total of fifty-five cows-twenty-one Angoni (Zebu), sixteen Boran (Zebu) and eighteen Barotse (Sanga) -5 to 7 years old, was kept in paddocks from October 1968 till the end of March 1969. Throughout the experimental period, a continuous 24-hr watch was kept on the animals. During the hours of darkness the use of artificial light was kept to a minimum. The onset of oestrus was determined by the cow's acceptance of an attempt by a virile vasectomized bull to mount. The cow was then immediately removed and placed in another paddock where she was teased with a different bull every $\frac{1}{2} \mathrm{hr}$ till she stopped accepting the male. By this procedure, it was possible to establish the time of onset and, to within $30 \mathrm{~min}$, the length of the oestrous period.

The time of ovulation was determined in thirty-one animals (eleven Angoni, ten Barotse, ten Boran) for a total of forty-two cycles. Twelve hours after the

\footnotetext{
* Present address: Department of Anatomy, Medical School, University of Rhodesia, Salisbury.
} 
onset of heat, the ovaries were palpated per rectum at 2-hr intervals till ovulation was detected.

Ghanges in the cervical os and in the vagina of eight normally cycling animals were followed by the aid of a Coldlite vaginoscope for three cycles. Four additional animals - two with ovarian cysts and two 'silent' or non-behavioural ovulators-were also included. Daily photographs of the cervical os were taken.

Rectal palpation was carried out on all animals once a week and changes in the ovaries were noted.

\section{RESULTS}

A total of 333 oestrous cycles was observed (Angoni, 127; Barotse, 108; and Boran, 98). Cycle lengths averaged $21 \cdot 89 \pm 1 \cdot 64,22 \cdot 68 \pm 3 \cdot 68$ and $24 \cdot 25 \pm 2 \cdot 27$ days, respectively. There was no significant difference between the lengths of the oestrous cycles in the three breeds $(P>0.05)$. Moreover, forty-three cycles, representing $13 \%$ of the total, were associated with silent ovulation.

Time of onset of oestrus

The results are demonstrated in Text-fig. 1. The onset of heat was observed on 396 occasions. Onsets occurring within a 2-hr interval were grouped and

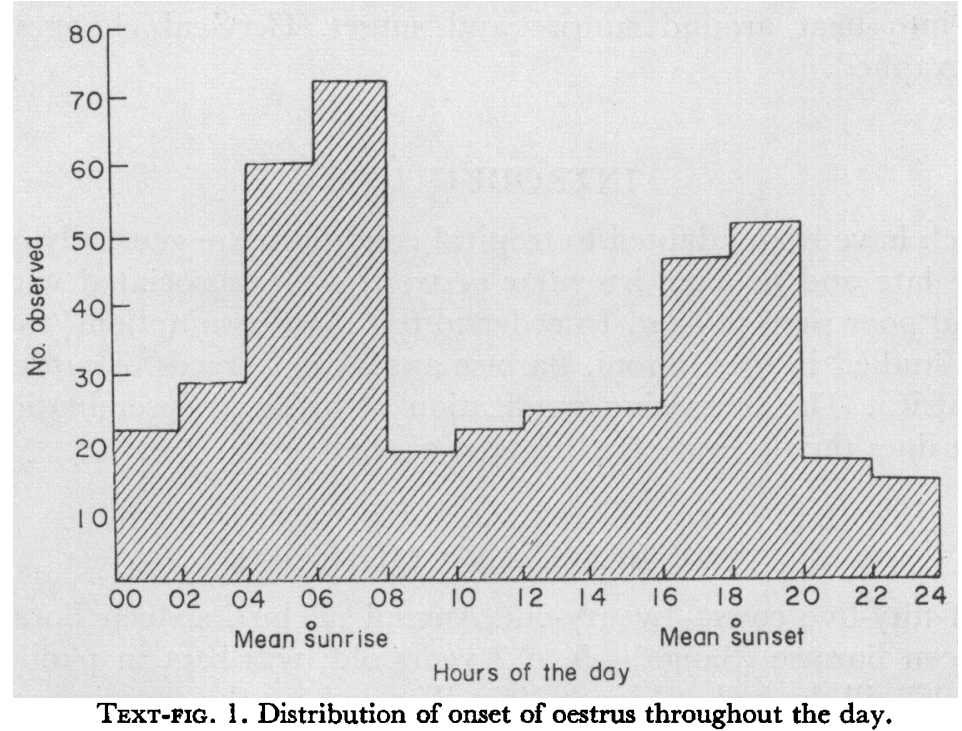

subjected to chi-square analysis, assuming an equal distribution throughout the day. The frequency of onset varied significantly between the periods of the day $(P<0.05)$. The time of activity seemed to be bimodal, and was centred around sunrise and sunset. Moreover, $55.6 \%$ of the onsets were observed during the morning periods and this was significantly higher than those occurring during the rest of the day.

A total of 396 oestrous periods was observed for the three breeds. There was no 
PLATE 1

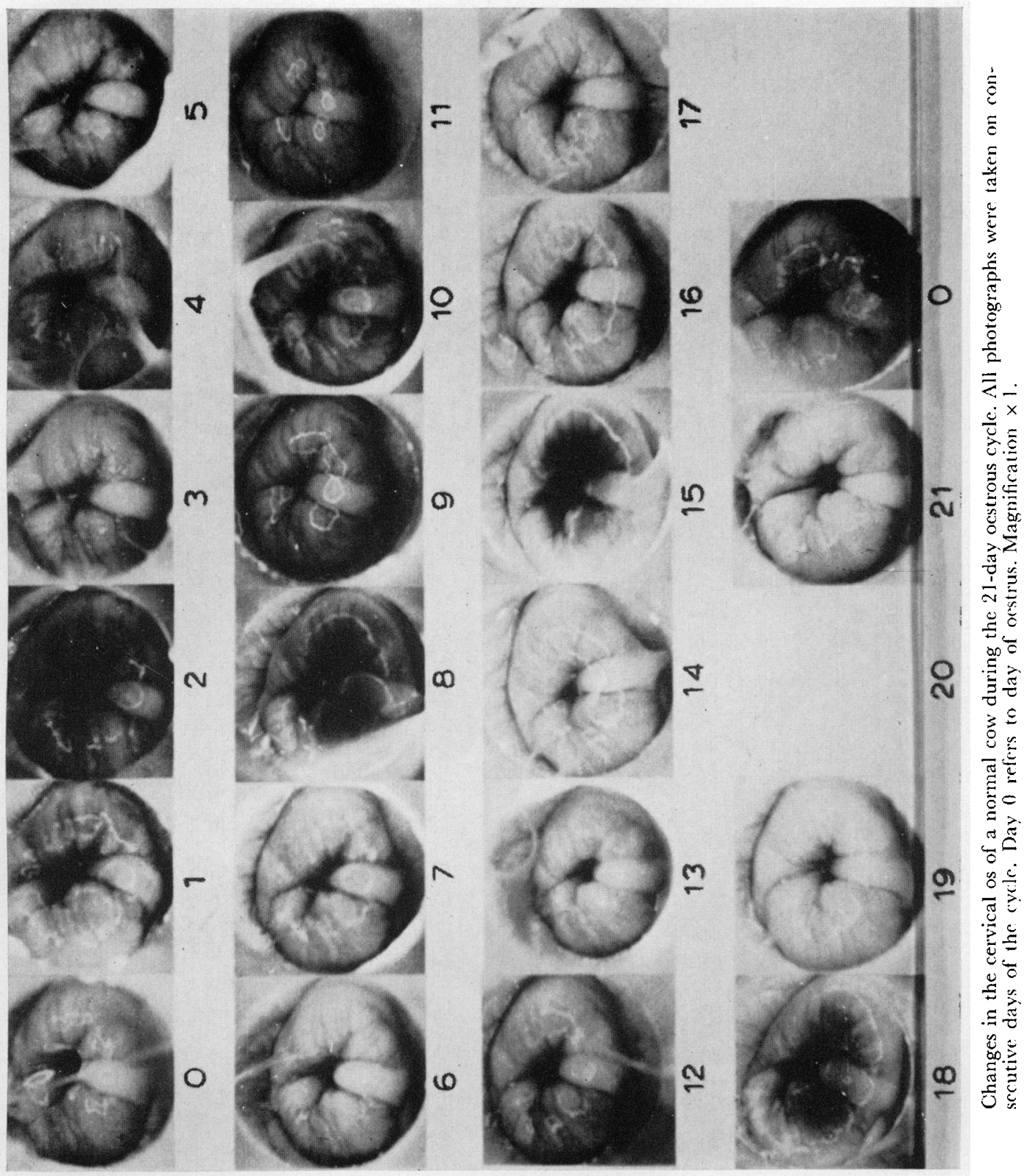

(Facing p. 412) 
significant difference $(P>0.05)$ in the duration of oestrus between the Angoni $(16.26 \pm 1.08 \mathrm{hr}$ ), Barotse $(17.43 \pm 1.18 \mathrm{hr})$ and Boran $(14.79 \pm 3.03 \mathrm{hr})$ breeds. Ovulation occurred $31.5 \pm 1.45 \mathrm{hr}$ from the time of onset of oestrus, and there was no significant difference between the three breeds.

Although the manifestations of oestrus were not very pronounced, a few days before the onset of oestrus some of the cows tended to be restless, and would follow and lick the bull. A short period before the onset of oestrus, they mounted other cows, bellowed and then stood to be mounted. Clear mucus was observed on the tail and on the labia long after the onset of oestrus.

\section{Cervical changes}

The present study shows that cervicoscopic photography in the cow is possible (Plate 1) by the aid of a Coldlite vaginoscope. Changes in the size, colour, appearance and contents of the cervical os followed the pattern previously described by Bane \& Rajakoski (1961). No single parameter could be used independently to predict oestrus accurately, as it was not unusual to observe a dilated or pink cervical os at any stage of the cycle. It was unusual, however, to observe the full complement of changes except during oestrus.

In animals with ovarian cysts, the changes in the vestibule and cervical os fluctuated without any distinct pattern. Animals with silent ovulations did not show the pronounced cyclical changes observed in the vestibule and cervical os of normally cycling cows and it was difficult to diagnose the exact day of oestrus.

\section{DISCUSSION}

The present results show that the oestrous cycle lengths of Zebu and Sanga cattle in the conditions of Central Africa are not different from the lengths, 17 to 24 days, for other breeds of cattle (Nalbandov \& Casida, 1942; Asdell, Alba \& Roberts, 1949; Hansel \& Trimberger, 1952). Similarly, the oestrous periods and the time of ovulation are not different. The psychic signs of heat are detectable in animals that show standing oestrus although the intensity was much less when compared to breeds of cattle in more temperate regions.

The bimodal distribution of the onset of oestrus would imply that heat could be detected efficiently if animals were observed around sunrise and sunset. Taking into account the duration of oestrus and the time of ovulation, a fairly accurate recommendation can be made on the time to inseminate.

The combination of changes in the cervical os, vestibule and mucus were satisfactory in detecting oestrus and its approach in normal cycles, though no parameter could be used singly for accurate prediction. Bane \& Rajakoski (1961) showed that, during the oestrous cycle, two waves of follicular growth occur. This could explain the dilatation of the cervical os noted in several animals about mid-cycle (Plate 1, Figs. 8, 9 and 10), and which was occasionally accompanied by increased tone in the uterus.

If one assumes that cattle in a tropical environment are exposed to extreme temperature stress, a high preponderance of silent ovulations would be expected (Hafez, 1962; Bond, 1967). This was not borne out by the present results as silent ovulation occurred in only $13 \%$ of all cycles. In animals with silent 
ovulation, the changes in the vestibule and cervical os were not diagnostic, a finding which is not in agreement with the hypothesis of Bane \& Rajakoski, (1961).

\section{ACKNOWLEDGMENTS}

The authors are indebted to $\mathrm{Mr} \mathrm{J}$. Nguluwe and Y. Kapyanga for their technical assistance.

\section{REFERENGES}

Asdell, S. A., Alba, S. \& Roberts, S. J. (1949) Studies on the estrous cycle of dairy cattle; cycle length, size of the corpus luteum and endometrial changes. Cornell Vet. 39, 389.

Bane, A. \& Rajakoski, E. (1961) The bovine estrous cycle. Comell Vet. 51, 77.

BoNd, J. (1967) Environment and reproduction. In: Factors Affecting Calf Crop, p. 179. Eds. T. J. Cunha, A. C. Warnick and M. Koger. University of Florida Press, Gainesville.

HAFEz, E. S. E. (1962) Behavioral estrus and ovulatory cycle in superovulated cattle. Am. Zoologist, $2,413$.

Hansel, W. \& Trmmerger, G. W. (1952) The effect of progesterone on ovulation time in dairy heifers. 7. Dairy Sci. 35, 65 .

Nalbandov, A. \& Gasioa, L. E. (1942) Ovulation and its relation to estrus in cows. J. Anim. Sci. 1, 189. 